\title{
Clinical Reasoning: A 54-year-old man with dyspnea and muscle weakness
}

Anibal Chertcoff, MD, Miguel Saucedo, MD, Lucrecia Bandeo, MD, Fátima Pantiu, MD, Luciana León Cejas, MD, Eduardo Borsini, MD, Ricardo Reisin, MD, and Bjarne Udd, MD, PhD

Neurology ${ }^{\circledR}$ 2019;92:e1136-e1140. doi:10.1212/WNL.0000000000007040
Correspondence

Dr. Chertcoff

anibalchertcoff@gmail.com

\section{Section 1}

A 54-year-old man was referred due to a 15-year history of unexplained dyspnea and progressive muscle weakness. The patient had an unremarkable birth and development history. His mother also had dyspnea of unidentified cause and died suddenly at age 70 years. At age 40 , a reduced vital capacity (VC) was identified in pulmonary tests during a smoking cessation treatment. $\mathrm{He}$ was asymptomatic. At age 45, he developed dyspnea while playing tennis without "second wind" phenomenon or worsening with fasting. At that time, a creatine kinase (CK) level of 490 $\mathrm{U} / \mathrm{L}$ (normal <200 U/L) was identified during treatment with statins. These were stopped but no resolution was observed. At age 46, he was hospitalized for pneumonia. Chest X-ray only revealed elevation of right diaphragm. Despite resolution of the infection, he developed orthopnea and started sleeping in the sitting position. Due to the acknowledgment of diaphragmatic weakness and the persistence of elevated CK, chest specialists referred him to the neurology department.

Examination revealed unremarkable cognitive abilities, normal cranial nerves, appropriate neck strength with mild weakness (4/5) bilaterally on deltoids, iliopsoas, and quadriceps. Calf muscles were hypertrophic. The patient was unable to sit from a recumbent position without using his arms. He did not present paradoxical breathing. Muscle tone was normal. He had no atrophy, fasciculations, or scoliosis. His deep tendon reflexes were absent. Sensory and cerebellar examinations were normal. He lacked ptosis, diplopia, jaw claudication, or dysphagia. Weakness did not fluctuate throughout the day. He was on losartan $50 \mathrm{mg} / \mathrm{d}$ and clonazepam $1 \mathrm{mg} / \mathrm{d}$.

Pulmonary tests revealed a restrictive pattern with a predictive forced vital capacity of $48 \%$ with only mild deterioration during a decade of follow-up. A severe drop in the VC (>50\%) was observed in the supine position, indicating diaphragmatic weakness. An oral pyridostigmine trial did not improve VC. Polysomnography revealed reduced sleep efficiency, nocturnal hypoventilation, elevated central apneas $(10 / \mathrm{h})$, and a saturation below $90 \%$ during $71 \%$ of total sleep time. The patient did not present sleep-related symptoms.

\section{Questions for consideration:}

1. What is the clinical scenario?

2. What diagnoses should we consider?

\section{GO TO SECTION 2}

\footnotetext{
From the Departments of Neurology (A.C., M.S., L.B., F.P., L.L.C., R.R.) and Respiratory Medicine (E.B.), Hospital Británico de Buenos Aires, Argentina; Folkhälsan Institute of Genetics (B.U.), Helsinki University; Tampere Neuromuscular Center (B.U.), Tampere University and University Hospital; and Neurology Department (B.U.), Vaasa Central Hospital, Vaasa, Finland.

Go to Neurology.org/N for full disclosures. Funding information and disclosures deemed relevant by the authors, if any, are provided at the end of the article.
} 


\section{Section 2}

The patient presented with respiratory symptoms due to diaphragmatic weakness associated with proximal muscle involvement. Early neuromuscular respiratory insufficiency represents a particular diagnostic category requiring a different approach with distinct differential diagnoses. Patients present with early respiratory involvement while still ambulatory, as opposed to most patients with neuromuscular disorders, in whom breathing difficulties are a late event. Weakness of respiratory muscles can lead to insufficient ventilation, sleep-disordered breathing, and ineffective coughing. Dyspnea, orthopnea, accessory respiratory muscle use, hypercapnia, and hypoxemia, insomnia, daytime hypersomnolence, headache, fatigue, and predisposition to aspiration and pneumonia may be observed. ${ }^{1}$ Patients will generally be referred to respiratory medicine for subtle and progressive unexplained dyspnea and can frequently be misdiagnosed with obstructive sleep apnea, asthma, or chronic obstructive pulmonary disease. ${ }^{2}$ Fourteen percent of patients with myasthenia gravis and $3 \%$ of those with amyotrophic lateral sclerosis may present in this manner. ${ }^{3}$ The table shows a list of neuromuscular diseases associated with early respiratory failure.

Regarding our patient, the only notable laboratory result was an elevated CK of $455 \mathrm{U} / \mathrm{L}$. Sedimentation rate was $17 \mathrm{~mm}$ and thyroid-stimulating hormone $1.13 \mu \mathrm{U} / \mathrm{mL}$. $\mathrm{HIV}$, antinuclear antibodies, anti-DNA, anti-RO/SSA, antiLA/SSB, rheumatoid factor, acetylcholine receptor, and muscle-specific kinase antibodies were negative. Arterial blood gases and lactate were normal. EMG revealed small brief motor unit potentials with early recruitment in quadriceps, iliopsoas, and deltoid muscles without sharp waves, fibrillations, or myotonic discharges in limbs and paraspinal muscles. Routine nerve conduction studies and single-fiber EMG were normal. Cardiologic evaluation, ECG, and echocardiography were unremarkable.

\section{Questions for consideration:}

1. Where is the lesion located?

2. What other studies should we perform?

GO TO SECTION 3 
Table Neuromuscular diseases associated with early respiratory insufficiency as a form of presentation in adults (adapted from Pfeffer et al. ${ }^{2}$ )

Lower motor neuron/anterior horn cell disorder

Amyotrophic lateral sclerosis

Peripheral neuropathy

Guillain-Barré syndrome

Chronic inflammatory demyelinating polyneuropathy

Connective tissue diseases

Sarcoidosis

Paraneoplastic

Hematologic malignancy

Amyloidosis

Toxic neuropathy: Lead

Multifocal motor neuropathy

Neuralgic amyotrophy with phrenic neuropathy

Disorders of the neuromuscular junction

Myasthenia gravis

Myopathies

Acquired myopathies (autoimmune, inflammatory, toxic)

Sporadic late-onset nemaline myopathy associated with HIV, monoclonal gammopathies, and autoimmune disorders

Hereditary myopathies

Congenital myopathies ${ }^{a}$

Multiminicore disease, nemaline myopathy, centronuclear myopathy (SEPN1, NEB; ACTA1, KBTBD13; and DNM2, MEGF10)

Metabolic myopathies (adult-onset Pompe disease, ${ }^{a}$ mitochondrial myopathy, ${ }^{a}$ myophosphorylase deficiency, Debrancher deficiency)

Muscular dystrophies ${ }^{a}$

Myotonic dystrophy, type I (DMPK)

Limb girdle muscular dystrophy $2 \mathrm{I}$ and $2 \mathrm{C}-\mathrm{F}$

Myofibrillar myopathies (desmin, aB-crystallin, BAG3, filamin C, and $F H L 1$ )

TPM3 myopathy

Hereditary myopathy with early respiratory failure $(T T N)^{a}$

Oculopharyngodistal muscular dystrophy

Table adapted by permission from Pfeffer G, Povitz M, Gibson GJ, Chinnery PF. Diagnosis of muscle diseases presenting with early respiratory failure. J Neurol 2015;262:1101-1114; (c) 2018 Springer Nature.

${ }^{a}$ Frequent form of presentation. 


\section{Section 3}

The patient's history of progressive respiratory symptoms due to diaphragmatic weakness, proximal muscles involvement, elevated CK, myopathic EMG, and family history of unexplained dyspnea suggests a hereditary myopathy. Hence, a percutaneous biopsy of the left quadriceps was performed: specimens showed preserved muscle structure with normal histochemistry and electron microscopy.

The most common hereditary myopathies presenting like the aforementioned include adult Pompe disease, myotonic dystrophy, and congenital and mitochondrial myopathies. ${ }^{3,4}$ Pompe disease, also named glycogen storage disease type II, is an autosomal recessive condition due to mutations in the gene encoding the lysosomal enzyme acid $\alpha$-glucosidase (GAA). Primary symptoms in one-third of the adult patients are those of respiratory insufficiency while still ambulatory. The most common symptom pattern is lower limb girdle and truncal muscular weakness combined with exercise intolerance and CK elevation. EMG usually reveals a myopathic pattern with myotonic-like discharges in limb and paraspinal muscles. Muscle pathology may reveal a vacuolar myopathy with excess glycogen storage and increased acid phosphatase staining. Early treatment with enzyme replacement may prevent progressive respiratory failure and subsequent death. ${ }^{5,6}$ Even though our patient's family history was discordant with a recessive inheritance pattern, a GAA assay using dried blood spot was done. The neutral/acid GAA activity ratio was 9.6 (normal <30) and the percentage of inhibition of acid GAA was $76 \%$ (normal $<89$ ), ruling out the disorder.

Mitochondrial myopathies are due to defects in either maternally inherited mitochondrial DNA or in the autosomally inherited nuclear genome also encoding mitochondrial proteins. Manifestations confined to striated muscle may include myalgia, exercise intolerance, proximal muscle weakness, external ophthalmoplegia, or facioscapulohumeral syndrome. Patients can also present with respiratory insufficiency due to brainstem or respiratory muscle involvement. Moreover, respiratory failure may be fulminant with mild limb weakness. Lactic acid is elevated and muscle fibers have a characteristic ragged-red fiber appearance. ${ }^{7}$ Our patient presented normal lactic acid and muscle biopsy.

Over the next years of follow-up, our patient developed progressive distal weakness and bilateral steppage gait. Due to his intolerance of the recumbent position, we could not perform an MRI, but a lower limbs CT scan showed bilateral fat replacement in quadriceps, iliopsoas, glutei, right anterior tibialis, extensor digitorum, and left hamstring (figure). With the aim of reaching a definite diagnosis, 3 possibilities were considered: (1) a second muscle biopsy, (2) a targeted genetic testing, and (3) a comprehensive gene panel.

\section{Question for consideration:}

1. How was the final diagnosis confirmed?

Figure Lower limbs CT scan

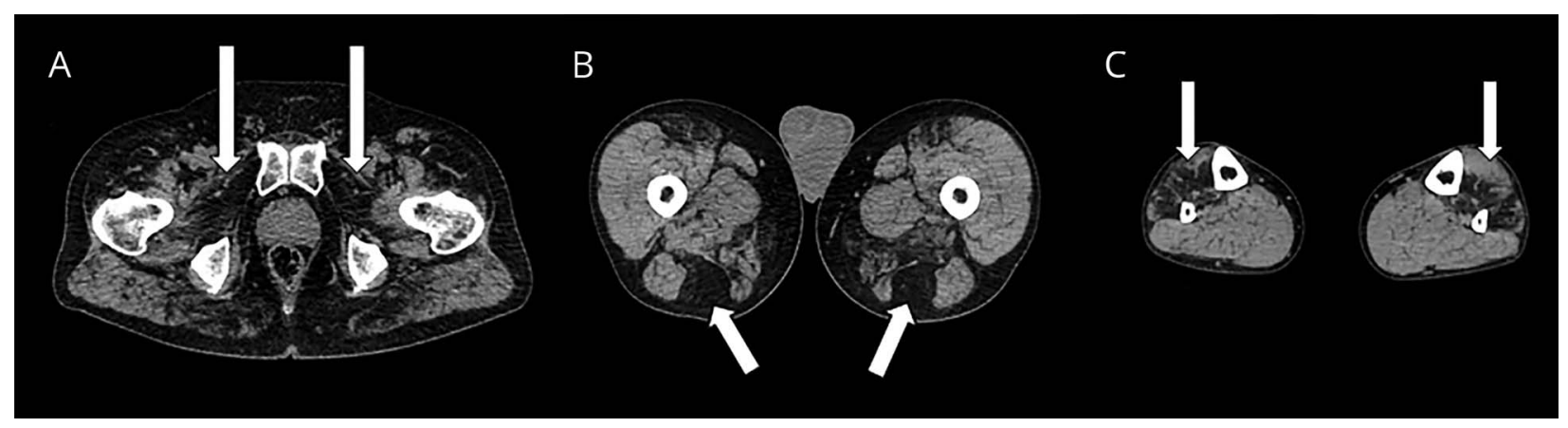

Fatty replacement was observed in (A) obturatorius pelvic muscles, (B) semitendinosus on thigh, and (C) anterolateral compartments muscles and tibialis posterior of the lower limbs.

GO TO SECTION 4 


\section{Section 4}

A DNA sample of the patient was sent to the Neuromuscular Research Unit of the University of Tampere in Finland. DNA was used for enrichment of a sequencing library using NimbleGen SezCap EZ choice Library protocol. The enrichment was done using the probes of MYOcap v3 gene panel targeting the exons of 265 genes known or predicted to cause muscular dystrophy or myopathy. A heterozygous mutation c.95351C > T p.A31784V in exon 344 of the TTN gene was identified. Mutations in this particular exon in this gene cause a titinopathy known as hereditary myopathy with early respiratory failure (HMERF).

Titin is the largest known polypeptide in nature and acts aiding in the myofibrillar assembly during myogenesis, determining the relaxed sarcomere length and regulating transcription. ${ }^{8}$ Mutations in the TTN gene may cause a range of skeletal muscle diseases and multiple cardiomyopathies. HMERF is an autosomal dominant slowly progressive myopathy that begins in the adult life presenting with gait disturbances related to distal or proximal limb weakness and progressive respiratory insufficiency. This disease, originally identified in Scandinavian populations, is now known to be distributed worldwide. Prevalence is unknown but it is probably underrecognized. Respiratory muscle weakness develops early in the disease course and can be the presenting symptom, usually including nocturnal hypoventilation, orthopnea, dyspnea on exertion, and daytime somnolence. Muscle weakness affects predominantly the lower limbs and frequently ankle dorsiflexion. Calf hypertrophy is frequent but calf atrophy can occur in a more advanced disease stage. CK is generally mildly elevated and MRI shows fatty replacement on affected muscles with the typical but not specific pattern of obturatorius, semitendinosus, and anterior and posterior tibial muscles. Findings in muscle biopsy may include multiple eosinophilic cytoplasmic inclusions in a necklace fashion, blue-rimmed vacuoles, myofibrillar abnormalities with Z-disc streaming, and electron-dense cytoplasmic bodies. ${ }^{9}$ Changes can be focal, with groups of several fibers showing marked alterations, whereas other regions might be less affected or even normal. Due to sampling and the focal nature of pathologic changes, muscle biopsy may sometimes be nonspecific. This can explain why our patient had normal muscle pathology despite findings on EMG and CT in the quadriceps muscle. Differential diagnoses include adult Pompe disease, myofibrillar myopathies, limb-girdle muscular dystrophy, facioscapulohumeral muscular dystrophy, mitochondrial myopathies, myasthenia gravis, and amyotrophic lateral sclerosis. ${ }^{2,10}$ There is no disease-modifying treatment; therapy includes the use of orthoses and mobility aids, physiotherapy, and respiratory support. ${ }^{10}$
Our case highlights the importance of considering early neuromuscular respiratory insufficiency as a distinctive syndrome leading to a challenging and broad differential diagnosis. Identifying the underlying condition has implications regarding specific and symptomatic treatment. A combination of muscle biopsy and genetic studies is still the best approach to hereditary myopathies. The former allows the structural characterization of the myopathy guiding the search for the most likely mutations. On the other hand, the identification of different mutations, especially those of unclear significance, requires correlation with structural abnormalities to confirm their pathogenicity.

\section{Author contributions}

A. Chertcoff: study concept and design, drafting of the manuscript, critical revision of the manuscript for important intellectual content. M. Saucedo: drafting of the manuscript, critical revision of the manuscript for important intellectual content. L. Bandeo: drafting of the manuscript, critical revision of the manuscript for important intellectual content. F. Pantiu: drafting of the manuscript, critical revision of the manuscript for important intellectual content. L. León Cejas: drafting of the manuscript, critical revision of the manuscript for important intellectual content. E. Borsini: drafting of the manuscript, critical revision of the manuscript for important intellectual content. R. Reisin: drafting of the manuscript, critical revision of the manuscript for important intellectual content. B. Udd: drafting of the manuscript, critical revision of the manuscript for important intellectual content.

\section{Study funding}

No targeted funding reported.

\section{Disclosure}

The authors report no disclosures relevant to the manuscript. Go to Neurology.org/N for full disclosures.

\section{References}

1. Boentert M, Wenninger S, Sansone VA. Respiratory involvement in neuromuscular disorders. Curr Opin Neurol 2017;30:529-537.

2. Pfeffer G, Povitz M, Gibson GJ, Chinnery PF. Diagnosis of muscle diseases presenting with early respiratory failure. J Neurol 2015;262:1101-1114.

3. Naddaf E, Milone M. Hereditary myopathies with early respiratory insufficiency in adults. Muscle Nerve 2017;56:881-886.

4. Jungbluth H, Voermans NC. Congenital myopathies: not only a paediatric topic. Curr Opin Neurol 2016;29:642-650.

5. Mellies U, Lofaso F. Pompe disease: a neuromuscular disease with respiratory muscle involvement. Respir Med 2009;103:477-484.

6. van der Ploeg AT, Clemens PR, Corzo D, et al. A randomized study of alglucosidase alfa in late-onset Pompe's disease. N Engl J Med 2010;362:1396-1406.

7. Koo P, Sethi JM. Metabolic myopathies and the respiratory system. Clin Chest Med 2018;39:401-410.

8. Savarese M, Sarparanta J, Vihola A, Udd B, Hackman P. Increasing role of Titin mutations in neuromuscular disorders. J Neuromuscul Dis 2016;3:293-308.

9. Palmio J, Evilä A, Chapon F, et al. Hereditary myopathy with early respiratory failure: occurrence in various populations. J Neurol Neurosurg Psychiatry 2014;85:345-353.

10. Tasca G, Udd B. Hereditary myopathy with early respiratory failure (HMERF): still rare, but common enough. Neuromuscul Disord 2018;28:268-276. 


\section{Neurology}

Clinical Reasoning: A 54-year-old man with dyspnea and muscle weakness

Anibal Chertcoff, Miguel Saucedo, Lucrecia Bandeo, et al.

Neurology 2019;92;e1136-e 1140

DOI 10.1212/WNL.0000000000007040

This information is current as of March 4, 2019

\section{Updated Information \&} Services

References

Subspecialty Collections

Permissions \& Licensing

Reprints including high resolution figures, can be found at: http://n.neurology.org/content/92/10/e1136.full

This article cites 10 articles, 1 of which you can access for free at: http://n.neurology.org/content/92/10/e1136.full\#ref-list-1

This article, along with others on similar topics, appears in the following collection(s):

\section{All Genetics}

http://n.neurology.org/cgi/collection/all_genetics

All Neuromuscular Disease

http://n.neurology.org/cgi/collection/all_neuromuscular_disease

All Sleep Disorders

http://n.neurology.org/cgi/collection/all_sleep_disorders

\section{CT}

http://n.neurology.org/cgi/collection/ct

Muscle disease

http://n.neurology.org/cgi/collection/muscle_disease

Information about reproducing this article in parts (figures,tables) or in its entirety can be found online at:

http://www.neurology.org/about/about_the_journal\#permissions

Information about ordering reprints can be found online:

http://n.neurology.org/subscribers/advertise

Neurology ${ }^{\circledR}$ is the official journal of the American Academy of Neurology. Published continuously since 1951, it is now a weekly with 48 issues per year. Copyright @ 2019 American Academy of Neurology. All rights reserved. Print ISSN: 0028-3878. Online ISSN: 1526-632X.

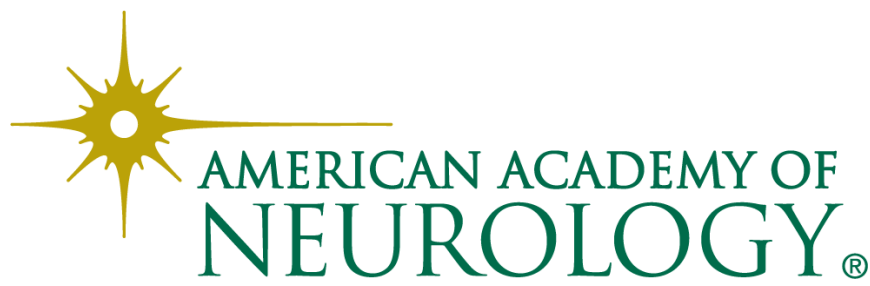

